\title{
BLOOD PRESSURE, PLASMA CATECHOLAMINES AND PROSTA- GLANDINS DURING ARTIFICIAL ERECTION IN A MALE TETRAPLEGIC
}

\author{
By H. L. Frankel, C. J. Mathias and J. J. Walsh \\ National Spinal Injuries Centre, Stoke Mandeville Hospital, Great Britain; and \\ Department of Neurology, Churchill Hospital, Oxford, Great Britain
}

\section{INTRODUCTION}

THE eliciting of erections and ejaculation in spinal man has been used in fertility studies and for artificial insemination. This was originally accomplished with intra-thecal neostigmine (Prostigmine) (Guttmann, I953, I96I; Guttmann \& Walsh, I97I), but in cervical and high thoracic lesions there were marked cardiovascular and autonomic changes such as hypertension, cardiac arrhythmias, headache, sweating and vomiting (Guttmann, I953; Guttmann \& Walsh, I97I). These were similar to the autonomic changes due to exaggerated sympathetic reflex activity in the isolated spinal cord during bladder percussion and muscle stimulation in such patients (Corbett et al., I971 $a, b$ ). Electrical sex stimulation using the Paraplegic Ejaculation Stimulator has been used successfully since I97I at the National Spinal Injuries Centre, Stoke Mandeville Hospital (Walsh, I974). Its effect on the haemodynamics, plasma catecholamines and plasma prostaglandins in a tetraplegic patient are reported here.

\section{SUBJECT AND METHODS}

A 3I-year-old manager, married and with no children, met with an accident while water skiiing five months previously. A fracture dislocation at $\mathrm{C}_{5}$ on $\mathrm{C}_{6}$ resulted in an incomplete tetraplegia, with complete motor loss below $\mathrm{C}_{7}$ and a few patches of sensory preservation below $\mathrm{C} 8$. No bladder and bowel sensations were present. He had erections but no emissions and had attempted sexual intercourse unsuccessfully. He enquired about sex stimulation on his own accord and requested it after being told the procedure and the possible dangers. The sex stimulation was accomplished using the Paraplegic Ejaculation Stimulator. After manual evacuation of the rectum, a probe was placed in the rectum close to the seminal vesicles and intermittent stimulation with up to 20 volts was given for a few seconds at a time. A rectal thermometer was inserted next to the probe and no temperature higher than $99^{\circ} \mathrm{F}$. was found. Pentolinium, Phentolamine and Propanolol were placed in syringes for administration if the blood pressure rose too high during stimulation. The resting blood pressure, measured by a sphygmomanometer was $130 / 80$ torr, and rose to a maximum of $180 / 100$ during stimulation. The rise in blood pressure was accompanied by a severe pounding headache, sweating and discomfort, which led to a discontinuation of the procedure.

On further request by the patient, stimulation was performed again. A tetrafluoroethylene catheter was inserted into the right dorsalis pedis artery. This 
was connected via saline-filled tubing to an electromanometer on a level with the fourth intercostal space, just anterior to the mid-axillary line (the phlebostatic axis, Winsor \& Burch, 1946). Between the catheter and the electromanometer was a device providing continuous perfusion of the catheter with sterile saline and series mechanical damping of the arterial pressure system by an adjustable stenosis (MacMillan \& Stott, I968). The blood pressure signal was used to trigger a beat-to-beat heart rate meter (Nielson, type 2750; Devices Instruments Ltd.), so that instantaneous heart rate was derived from the blood pressure signal. A 24-inch central venous catheter was inserted through the right ante-cubital vein into the right atrium. Its position was confirmed radiologically. This catheter was connected via saline-filled tubing to an electromanometer mounted in the phlebostatic axis. Blood pressure, heart rate and central venous pressure signals were amplified and continuously recorded on a four-channel rectilinear pen recorder (Devices, $\mathrm{M}_{4}$ ). Electric sex stimulation was given using the Paraplegic Ejaculation Stimulator, and using precautions stated before.

Both arterial and central venous catheters had three-way connectors which facilitated the taking of blood samples. Arterial blood samples for plasma catecholamines were collected at rest and during electrical stimulation. Methods of collection were similar to those described earlier (Debarge et al., 1974), and ensured that samples were not contaminated with perfusing fluid. The plasma catecholamines were measured using the modified double-isotope technique of Engelman and Portnoy (I970) (Christensen, I973).

Mixed venous blood for prostaglandin analysis was drawn from the catheter in the right atrium at the same time as arterial blood was drawn for catecholamines. Mixed venous blood from the right atrium was used for plasma prostaglandin analysis because enzymes like I5-hydroxy-prostaglandin dehydrogenase (Anggard \& Samuelsson, 1964) are known to be mainly responsible for removal of over 90 per cent of infused PGEI, PGE2 and PGF2 alpha during one passage through animal lung (Ferriera \& Vane, 1967; Piper et al., 1970). Similar metabolism is thought to occur in man. Immediately the blood sample had been taken from the patient, it was placed in ice-cooled lithium heparin tubes and spun in a centrifuge at $-4^{\circ} \mathrm{C}$. for ten minutes at 3,000 revolutions/minute. The plasma was immediately pipetted out, stored at $-20^{\circ} \mathrm{C}$. and Prostaglandin E (PGE) and Prostaglandin $F$ (PGF) were measured using a modification of the radioimmunoassay method of Hillier and Dilley (1974) (Hillier, I974).

\section{RESULTS}

On the first occasion, using a sphygmomanometer, the blood pressure was I30/80 torr resting and rose to I80/100 during stimulation. During the second occasion continuous blood pressure, heart rate and central venous pressure were recorded. Resting blood pressure varied between 85/60 and I IO/65 torr, heart rate between 90 and 100 beats/minute and mean central venous pressure between seven and nine torr. Electrical stimulation was given i I times and consistently caused a rise in blood pressure. On one occasion a seven-volt stimulus raised the blood pressure to a maximum of $255 / 1$ Io torr with the heart rate dropping to 65 beats/minute (fig. I). Raised blood pressure persisted for four to five minutes after stopping stimulation before return to the baseline. No headache and discomfort were reported from the patient on the second occasion, though sweating 


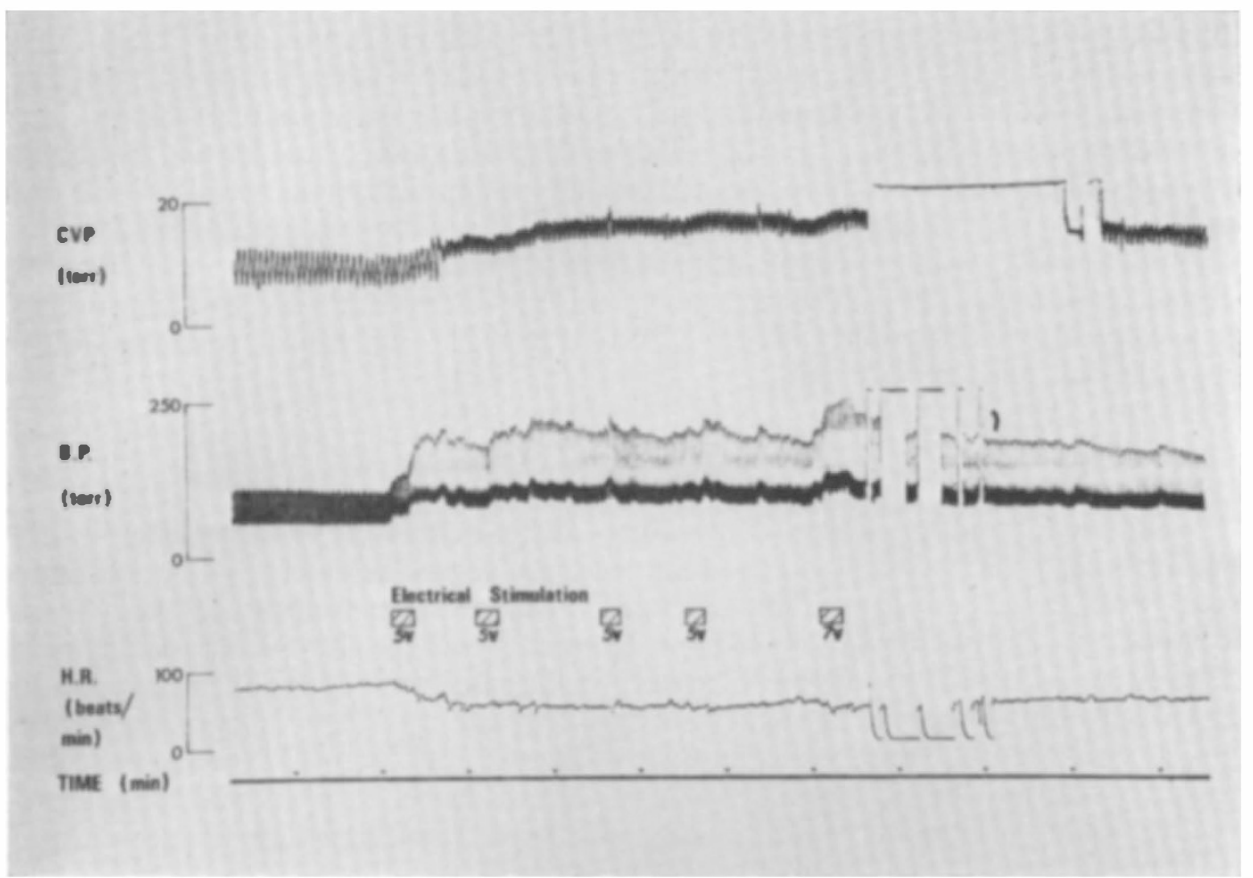

FIG. I

Central venous pressure (CVP), arterial blood pressure (BP), and heart rate (HR) before, during and after electrical stimulation with five or seven volts. Blood samples were taken at the times where the records are interrupted.

\section{TABLE I}

Haemodynamic, catecholamine and prostaglandin responses to electrical stimulation

\begin{tabular}{|l|r|r|r|}
\hline & Resting & Stimulation & $\begin{array}{c}\text { Percentage } \\
\text { change }\end{array}$ \\
\hline Systolic blood pressure (torr) & I IO & 230 & + I09 \\
Diastolic blood pressure (torr) & 65 & 90 & +38 \\
Mean blood pressure (torr) & 80 & I37 & +71 \\
Central venous pressure (torr) & 9 & 16 & +78 \\
Heart rate (beats/min) & IOO & 65 & -35 \\
Plasma noradrenaline (ng./ml.) & 0.19 & 0.44 & + II 17 \\
Plasma adrenaline (ng./ml.) & 0.03 & 0.06 & + I00 \\
Plasma prostaglandin E (ng./ml.) & 0.135 & 0.293 & + I32 \\
Plasma prostaglandin F (ng./ml.) & O.IOI & 0.055 & -46 \\
& & & \\
\hline
\end{tabular}


and flushing of the face occurred. The electric stimulation resulted in erection but no ejaculation. No untoward sequelae followed.

Plasma noradrenaline was $0.19 \mathrm{ng} . / \mathrm{ml}$. and plasma adrenaline $0.03 \mathrm{ng} . / \mathrm{ml}$. at rest. During one of the hypertensive phases (blood pressure of 230/90 torr) following electrical stimulation, plasma noradrenaline rose to $0.44 \mathrm{ng} . / \mathrm{ml}$. and plasma adrenaline to $0.06 \mathrm{ng} . / \mathrm{ml}$. (Table I). Using identical methods, resting levels of plasma noradrenaline and plasma adrenaline in normal subjects are 0.22 ng./ml. and $0.05 \mathrm{ng} . / \mathrm{ml}$. respectively (Christensen, I973), while resting levels in physiologically complete tetraplegics are $0.04 \mathrm{ng} . / \mathrm{ml}$. and $0.00 \mathrm{ng} . / \mathrm{ml}$. respectively (Debarge et al., 1974). PGE was $0.135 \mathrm{ng} / \mathrm{ml}$. at rest and rose to $0.293 \mathrm{ng} . / \mathrm{ml}$. with electrical stimulation (fig. 2). PGF was $0 \cdot 10 \mathrm{I} \mathrm{ng} . / \mathrm{ml}$. at rest and fell to $0.055 \mathrm{ng} . / \mathrm{ml}$. with stimulation.

\section{DISCUSSION}

Electrical stimulation was consistently accompanied by hypertension, sweating, flushing of the face and, on the first occasion, severe headache. These changes have been described in tetraplegic man during administration of intra-thecal neostigmine (Guttmann \& Walsh, I97I; Rossier et al., I97I). Similar occurrences have been reported following bladder percussion and muscle stimulation in tetraplegics and it has been suggested that they are caused by exaggerated reflex sympathetic nervous activity through the isolated spinal cord (Corbett et al., I974). The bradycardia during stimulation may be attributed to a carotid sinus baroreceptor reflex (Heymans \& Neil, I958) since both the afferent (glosso-pharyngeal) and efferent (vagal) parts of the arc are intact in spinal man.

The resting level of plasma noradrenaline and plasma adrenaline were near normal whereas in complete tetraplegics they are below normal. This may be a reflection of the incomplete spinal cord transection. During stimulation there was a marked rise in plasma noradrenaline (fig. 2) with a smaller rise in plasma adrenaline. Noradrenaline is the neurotransmitter at sympathetic adrenergic nerve endings and adrenaline is the principal secretion from the adrenal medulla. The marked rise in noradrenaline suggests an increase in sympathetic nervous activity during stimulation.

Cerebral haemorrhage from sympathetic overactivity in tetraplegic man has been reported following bladder distension (Thompson \& Witham, I948), during labour (Jung \& Schmidt, I962), and after intra-thecal neostigmine (Guttmann \& Walsh, I970). The Paraplegic Ejaculation Stimulator delivers shorter and better controlled stimulation than does neostigmine and avoids the prolonged hypertension which occurs with neostigmine. Nevertheless, large elevations of blood pressure for short periods can damage blood vessels in experimental animals (Goldby \& Beilin, I972), and continuous monitoring of blood pressure by arterial catheter is suggested for better control.

Levels of PGE in mixed venous blood rose from $0.135 \mathrm{ng} . / \mathrm{ml}$. to $0.293 \mathrm{ng} . / \mathrm{ml}$. (fig. 2), while PGF fell. Stimulation of nerves to the dog spleen and rabbit kidney causes an eflux of PGE and PGF (Davies et al., 1967; Ferreira \& Vane, 1967; Gilmore et al., I968; Davis \& Horton, 1972). Catecholamines have stimulated release of prostaglandin-like substances in animal organs (Ferreira \& Vane, 1967; McGiff et al., 1972). Increased levels of PGE in man have been reported in phaeochromocytoma (Sandler et al., 1968). In our patient, the increase in 
sympathetic nervous activity and increase in plasma catecholamines during stimulation have probably led to a release of PGE. This is similar to the increased levels of PGE seen in tetraplegic subjects during increased sympathetic nervous activity following bladder percussion (Frankel, Hillier \& Mathias, 1974). However, parasympathetic stimulation has caused release of prostaglandins in the rat stomach (Coceani et al., 1967; Bennet et al., 1967; Shaw \& Ramwell, 1968). In our patient there was pronounced vagal activity as indicated by bradycardia, and it may be that parasympathetic activity also played a part in the prostaglandin released. Prostaglandins themselves may also affect the sympathetic nervous

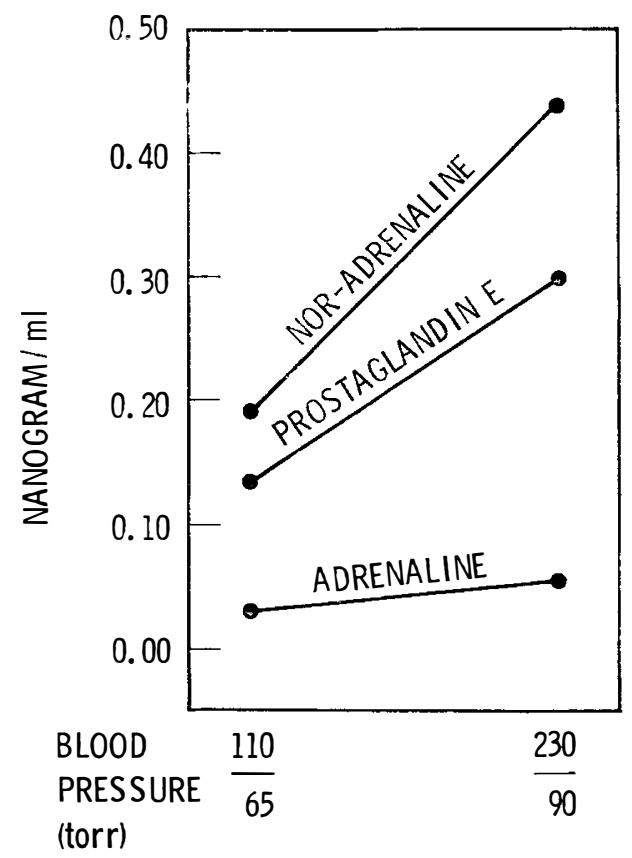

FIG. 2

Plasma noradrenaline, adrenaline and prostaglandin $\mathrm{E}$, and blood pressure, before and after electrical stimulation.

system and may be involved in its feedback control (Hedqvist, 1973). Infusion of PGE inhibits transmitter release in response to sympathetic nerve stimulation in the cat spleen and rabbit heart (Hedqvist, I970; Hedqvist \& Wennmalm, I97I), and also inhibits release of dopamine $\beta$-hydroxylase in the stimulated vas deferens. (Johnson et al., I97I). PGE reduces the pressor response to noradrenaline (Bergstrom et al., I964), and antagonises the action of sympathetic amines on smooth muscle (Clegg, I966). It is not known whether the demonstrated levels. of PGE in our tetraplegics are capable of producing similar effects. Our evidence indicates that stimulation produces a substantial rise in PGE and that this is likely to be due to sympathetic overactivity in the isolated spinal cord. PGE itself influences sympathetic activity, but its importance in tetraplegic man has yet to be determined. 


\section{SUMMARY}

I. A male tetraplegic patient received electrical stimulation to cause penile erection. On one occasion blood pressure recorded by sphygmomanometer rose from I30/80 torr to I80/100 torr. On a subsequent occasion blood pressure and heart rate were continuously recorded using an arterial catheter. During stimulation, blood pressure rose from I IO/65 torr to $255 /$ I IO torr. It is suggested that whenever such stimulation is used, blood pressure should be monitored continuously using similar methods.

2. Plasma noradrenaline and plasma adrenaline were estimated during the resting stage and during stimulation. Plasma noradrenaline rose markedly, suggesting an increase in sympathetic nervous activity.

3. Plasma Prostaglandin E and Prostaglandin F were estimated before and during stimulation. A large elevation in Prostaglandin E occurred. Its release could be a result of sympathetic nervous activity.

Acknowledgements. We wish to thank Dr. N. J. Christensen of the 2nd Clinic of Internal Medicine, Kommunehospitalet, Arhus, Denmark, for the plasma catecholamine analysis, Dr. K. Hillier, of the Nuffield Department of Obstetrics and Gynaecology, John Radcliffe Hospital, Oxford, for the prostaglandin estimations, and Dr. J. M. K. Spalding, Consultant Neurologist, Oxford, for encouragement and advice.

\section{REFERENCES}

ANgGard, E. \& SAmuelsson, B. (1964). Metabolism of prostaglandin $\mathrm{E}_{1}$ in guinea pig lung: the structure of two metabolites. F. Biol. Chem. 239, 4097.

BennetT, A., Friedman, C. A. \& VANe J. R. (1967). Release of prostaglandin E $_{1}$ from the rat stomach. Nature (Lond.), 216, 873.

Bergstrom, S., Carlson, L. A., Ekelund, L.-G. \& Orö, L. (1965). Cardiovascular and metabolic response to infusions of prostaglandin $\mathrm{E}_{1}$ and to simultaneous infusions of noradrenaline and prostaglandin $\mathrm{E}_{1}$ in man. Acta physiol. scand. 64, 332.

Christensen, N. J. (I973). Plasma noradrenaline and adrenaline in patients with thyrotoxicosis and myxoedema. Clin. Sci. and Mol. Med. 45, I63.

ClegG, P. C. (1966). Antagonism by prostaglandins of the responses of various smooth muscle preparations to sympathomimetics. Nature (Lond.), 209, I 137.

Coceani, F., Pace-Asciak, C., Volta, F. \& Wolfe, L. S. (1967). Effect of nerve stimulation on prostaglandin formation and release from the rat stomach. Am. F. Physiol. 213, 1056.

Corbett, J. L., Debarge, O., Frankel, H. L. \& Mathias, C. J. (1974). Cardiovascular responses in tetraplegic man to muscle spasm, bladder percussion and hypercapnia. Proc. Symp. on Physiol. and Pharmacol. control of blood pressure, Internat. Union Physiol. Sciences., Melbourne, Australia. In Clinical and Experimental Pharmacology and Physiology (in press).

Corbett, J.'L., Frankel, H. L. \& Harris, P. J. (I97Ia). Cardiovascular changes associated with skeletal muscle spasm in tetraplegic man. F. Physiol. (Lond.), 215, 381.

Corbett, J. L., Frankel, H. L. \& Harris, P. J. (I971 $b$ ). Cardiovascular reflex responses to cutaneous and visceral stimuli in spinal man. F. Physiol. (Lond.), 21 5, 395.

Davies, B. N., Horton, E. W. \& Withrington, P. G. (I967). The occurrence of prostaglandin $\mathrm{E}_{2}$ in splenic venous blood following nerve stimulation. F. Physiol. (Lond.), I88, 38P.

Davis, H. A. \& Horton, E. W. (I972). Output of prostaglandin from the rabbit kidney, its increase on renal nerve stimulation and its inhibition by Indomethacin. Brit. $\mathcal{F}$. Pharmacol. 46, 658.

Debarge, O., Christensen, N. J., Corbett, J. L., Eidelman, B. H., Frankel, H. L. \& Mathias, C. J. (1974). Plasma catecholamines in tetraplegics. Paraplegia, 12, 44. 
Engelman, K. \& Portnoy, B. (1970). A sensitive double-isotope derivative assay for norepinephrine and epinephrine. Normal resting human plasma levels. Circulation Res. 26, 53.

FerReira, S. H. \& VANE, J. R. (1967). Prostaglandins: their disappearance from and release into the circulation. Nature (Lond.), 216, 868.

Frankel, H. L., HillieR, K. \& Mathias, C. J. (I974). Unpublished observations.

Gilmore, N., VANE, J. R. \& Wyllie, J. H. (I968). Prostaglandins released by the spleen. Nature (Lond.), 218, I 135.

GoldBY, F. S. \& BeIlin, L. J. (1972). How an acute rise in arterial pressure damages arterioles. Cardiovasc. Res. 6, 569.

Guttmann, L. (1953). Sexual Disturbances: British Medical History of World War II: Vol. Surgery, p. 482 . London: H.M. Stationery Office.

Guttmann, L. (196I). The sexual problem in spinal paraplegia. Proc. Scient. Meeting, Internat. Stoke Mandeville Games, Rome, p. 63.

GuttmianN, L. \& Walsh, J. J. (I97I). Prostigmine assessment test of fertility in spinal man. Paraplegia, 9, 40.

Heymans, C. \& NeIL, E. (I958). Reflexogenic Areas of the Cardiovascular System. London: Churchill.

HiLliER, K. (I974). Personal communication.

HillieR, K. \& Dilley, F. R. (1974). Separation and radioimmunoassay of F- $a$-prostaglandin using a silica gel micro-column. Prostaglandins, 5, I37.

HedQvist, P. (1970). Control by prostaglandin $\mathrm{E}_{2}$ of sympathetic neurotransmission in the spleen. Life Sci. 9, 269 (Part I).

HedQvist, P. (1973). Autonomic Neurotransmission. Prostaglandins, vol. I, ed. P. W. Ramwell, p. IOI. New York: Plenum Press.

HedQvist, P. \& WenNmalm, A. (I97I). Comparison of the effects of prostaglandins $\mathrm{E}_{1}$, $\mathrm{E}_{2}$ and $\mathrm{F}_{2}$ in the sympathetically stimulated rabbit heart. Acta physiol. scand. 83, I 56

Johnson, B. G., ThoA, N. B., Weinshilboum, R., Axelrod, J. \& Kopin, I. J. (I97.I). Enhanced release of dopamine hydroxylase from sympathetic nerves by calcium and phenoxybenzamine and its reversal by prostaglandins. Proc. Nat. Acad. Science, U.S.A., 68, 2227.

Jung, H. \& SchmidT, K. (I962). 2nd Geburt nach Querschnittslähmung. 2 bl. Gynäkol. 84, IIO5.

McGiff, J. C., Crowshaw, K., Terrango, N. A., Malik, K. U. \& Lonigro, A. J. (I972). Differential effect of noradrenaline and renal nerve stimulation on vascular resistance in the dog kidney and the release of a prostaglandin E-like substance. Clin. Sci. 42, 223.

MacMillan, A. L. \& StotT, F. D. (1968). Continuous intra-arterial blood pressure measurement. Bio-med. Engineering, 3, 20.

Piper, J., VANe, J. R. \& Wyllie, J. H. (I970). Inactivation of prostaglandins by the lung. Nature (Lond.), 225, 600.

Rossier, A. B., Ziegler, W. H., Duchosal, P. W. \& Meylan, J. (I97I). Sexual function and dysreflexia. Paraplegia, 9, $5 \mathrm{I}$.

SANDler, M., Karim, S. M. M. \& Williams, E. D. (I968). Prostaglandins in aminepeptide secreting tumours. Lancet, ii, I053.

Shaw, J. E. \& RAMWELL, P. W. (I968). Inhibition of gastric secretion in rats by prostaglandin $\mathrm{E}_{1}$. Prostaglandin Symp. of the Worcester Foundation for Exptl Biol., ed. P. W. Ramwell and J. E. Shaw, p. 55. New York: Interscience.

Thompson, C. B. \& Witham, A. (I948). Paroxysmal hypertension in spinal cord injuries. New Eng. F. Med. 239, 291.

WaLSH, J. J. (I974). Unpublished observations.

Winsor, T. \& BURCH, G. W. (I964). Use of the phlebomanometer. Amer. Heart f. 31, 387. 